\title{
Water Consumption in Inner Mongolia Reach of the Yellow River since Integrated Regulation
}

\author{
Jin Shuangyan, Zhang Suiye, Ma Zhijin \\ Yellow River Institute of Hydrology and Water Resources, Zhengzhou, China, 450004
}

\begin{abstract}
Keywords: water consumption; water diversion-recession method; water balance method; water diversion quantity; water recession quantity; Inner Mongolia reach; integrated water regulation
\end{abstract}

\begin{abstract}
The annual allocation, inter-annual variation and relationship of water diversion and recession are analyzed in Inner Mongolia reach of the Yellow River main stream from 1999 to 2011. Water consumption in Inner Mongolia reach is calculated by method of water diversion-recession and water balance. The mean water consumption of water diversion and recession method is 7.544 billion $\mathrm{m}^{3}$ and annual variation is relatively steady. The result of water balance method is 5.672 billion $\mathrm{m}^{3}$ and annual variation is obvious. It is suggested that strengthen verification of entrances and monitoring of water diversion and recession.
\end{abstract}

\section{Introduction}

Background. The Yellow River water regulation implements double control principles, i.e. total water consumption and discharge of control section. Water diversion of Yellow River main stream in Inner Mongolia reach are mainly from irrigation, industry and urban living water, water recession mainly related to irrigation and industry water structure. Thus, proportion and scale of water diversion and recession and water consumption in Inner Mongolia reach since integrated regulation are needed to analyze for united management and optimal configuration of the Yellow River water resources.

Basic data.Integrated water resources regulation of Yellow River began in March 1999, so the year from 1999 to 2011 is selected as study period. Water diversion-recession data are from monthly report of water diversion project approved by Yellow River Conservancy Commission. Hydrology data of in main stream and tributaries of Yellow River are from Yellow River basin hydrological almanac.

\section{Method}

Method of water diversion and recession.For particular river section, water consumption is the difference of water diversion and water recession, based on the calculation of observed water diversion and water recession.

$$
W_{C}=W_{D}-W_{R}
$$

Where: $W_{C}$, water consumption; $W_{\mathrm{D}}$, water diversion; $W_{\mathrm{R}}$, water recession.

Method of water balance. Water balance method is based on the observed data of hydrological station, and evaporation and leakage loss were deducted from the difference of upper and lower section discharge, according to the principle of water balance. The equation is as follows:

$$
W_{\mathrm{C}}=\left(W_{\mathrm{U}}+W_{\mathrm{S}}+W_{\mathrm{UC}}\right)-\left(W_{\mathrm{E}} \pm W_{\mathrm{L}}\right)-W_{\mathrm{L}}
$$

Where: $W_{\mathrm{U}}$, upper reach inflow; $W_{\mathrm{L}}$, lower reach effluent; $W_{\mathrm{S}}$, controlled water quantity; $W_{\mathrm{UC}}$, uncontrolled water quantity; $W_{\mathrm{E}}$, water surface evaporation; $W_{\mathrm{L}}$, section channel leakage; $W_{\mathrm{C}}$, industrial and agricultural water consumption.

According to features of the Yellow River, the interval water consumption of industry and agriculture has its special definition. Water consumption of agricultural irrigation refers to the water which can't return to the Yellow River due to evaporation and leakage in irrigation process of farmland, grassland, forest and so on. Water consumption of industrial and urban domestic includes user consumption and drainage loss, i.e. difference of water diversion and waste water into rivers. 
Water surface evaporation was calculated by observation data of the representative rainfall and evaporation stations year by year. Evaporating observation data of different evaporating dish are modified according to the coefficient given by the second national comprehensive planning of water resources. Water surface area is multiplied by mean width of monthly water surface, according to the data in Yellow River basin hydrology almanac, and distance between upper and lower station. The equation is as follows:

$$
\mathrm{W}_{\mathrm{E}}=((E \times a)-P) \times \mathrm{A}
$$

Where: $W_{\mathrm{E}}$, net evaporation, $10^{8} \mathrm{~m}^{3} ; E$, mean annual evaporation, mm; $a$, conversion coefficient of different evaporating dish; $P$, average rainfall, $\mathrm{mm} ; A$, water surface area, $\mathrm{km}^{2}$.

\section{Analysis of water diversion and water recession}

Entrance number of water diversion-recession. There are forty water diversion entrances in Inner Mongolia reach approved by Yellow River Conservancy Commission in 2010, shown in Table 1. One locates upper Shizuishan, three between Shizuishan and Bayangaole, zero between Bayangaole and Sanhuhekou, six between Sanhuhekou and Toudaoguai, and twenty-nine locate lower Toudaoguai.

In order to reflect the real status of water diversion and recession, remote sensing images of thirty meters resolution in Google earth were applied, and one hundred and one entrances of water diversion and water recession were identified from Shizuishan to Toudaoguai.

Table 1 Water diversion from Yellow River in Inner Mongolia unit: $10^{4} \mathrm{~m}^{3}$

\begin{tabular}{|c|c|c|c|c|c|c|c|}
\hline Section & $\begin{array}{c}\text { License } \\
\text { No. }\end{array}$ & $\begin{array}{c}\text { Water } \\
\text { Diversion }\end{array}$ & $\begin{array}{c}\text { approval } \\
\text { water }\end{array}$ & $\begin{array}{c}\text { Sectio } \\
n\end{array}$ & $\begin{array}{c}\text { License } \\
\text { No. }\end{array}$ & $\begin{array}{c}\text { Water } \\
\text { Diversion }\end{array}$ & $\begin{array}{c}\text { approval } \\
\text { water }\end{array}$ \\
\hline \multirow{2}{*}{$\begin{array}{l}\text { Upper } \\
\text { Shizuis }\end{array}$} & \multirow{2}{*}{$\begin{array}{c}\text { No.410 } \\
01\end{array}$} & \multirow{2}{*}{$\begin{array}{l}\text { E Rong } \\
\text { dianchang }\end{array}$} & \multirow{2}{*}{1736} & \multirow{11}{*}{$\bar{Z}$} & No.41012 & Madihao & 6000 \\
\hline & & & & & No.41013 & putanguai & 6100 \\
\hline \multirow{3}{*}{$\begin{array}{c}\text { Shizuis } \\
\text { han } \\
\sim\end{array}$} & No.410 & Nan'anganqu & 39264 & & No.41014 & Hushiyinhu & 6300 \\
\hline & No.410 & Shenwuganqu & 45000 & & No.41015 & Xiaoshawa & 4700 \\
\hline & No.410 & Beizongganqu & 432000 & & No.41016 & Xiatan & 55 \\
\hline \multirow{6}{*}{$\begin{array}{c}\text { Sanhuh } \\
\text { ekou } \\
\sim \\
\text { Toudao } \\
\text { guai }\end{array}$} & No.410 & Baogangshuiy & 12000 & & No.41017 & Hekou & 200 \\
\hline & No.410 & Huajiangyingz & 7000 & & No.41018 & Dongyingzi & 100 \\
\hline & No.410 & Baotoudaqi & 4430 & & No.41019 & Haojiaao & 80 \\
\hline & No.410 & Dengkoushuic & 1500 & & No.41020 & Haishengbu & 70 \\
\hline & No.410 & Dengkoudianli & 26000 & & No.41021 & Maobula & 1000 \\
\hline & No.410 & Tuanjiequ & 7000 & & No.41022 & Section of & 865 \\
\hline
\end{tabular}

Analysis of water diversion. The average annual water diversion in Inner Mongolia reach from 1999 to 2011 is 6.735 billion $\mathrm{m}^{3}$, which showed slowly increasing trend. From temporal distribution, water diversion is mainly occurred in April to November, which just relates to irrigation season and occupies $98.3 \%$ of total amout. From spatial distribution, water diversion is mainly occurred in the section from Shizuishan to Bayangaole, which occupies $89.2 \%$ of total amount.

Analysis of water recession. The average annual water recession in Inner Mongolia reach is 1.071 billion $\mathrm{m}^{3}$, which showed slowly increasing trend. From temporal distribution, water recession is mainly occurred in April to November which occupies $85.3 \%$ of total amount. From spatial distribution, water recession is mainly occurred in Bameng, between section from Bayangaole to Sanhuhekou, which includes two parts water quantity of North zongganqu and Xishanzui hydrology station.

Relationship between water diversion and water recession.The average ratio of water recession and water diversion in HeTao Irrigation Area (HTIA) of Inner Mongolia is 0.16, shown in Fig.1. The relationship between water recession and diversion is very well, i.e. larger water diversion and larger water recession, shown in Fig.2. 

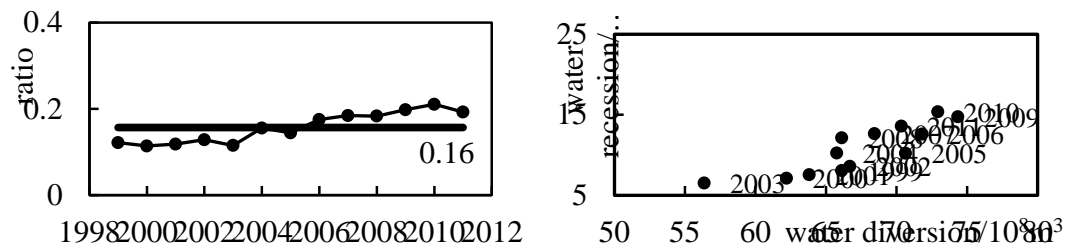

Fig.1 Ratio of water diversion-recession in HTIA

Fig.2 Relation of water diversion-recession in HTIA

\section{Analysis of water consumption}

Results of water diversion-recession method.Considering water diversion mainly occurred in the section of Shizuishan to Bayangaole, while water recession occurred in Bayangaole to Sanhuhekou, in order to avoid negative water diversion phenomenon appeared in the section of Bayangaole to Sanhuhekou, the Inner Mongolia reach of Yellow River is divided into four parts, i.e. upper Shizuishan, Shizuishan Sanhuhekou, Sanhuhekou Toudaoguai and lower Toudaoguai.

The average water consumption in Inner Mongolia reach is 5.672 billion $\mathrm{m}^{3}$. The four sections are 0.034 billion, 5.061 billion, 0.43 billion and 0.146 billion $\mathrm{m}^{3}$ respectively, shown in Fig.3.

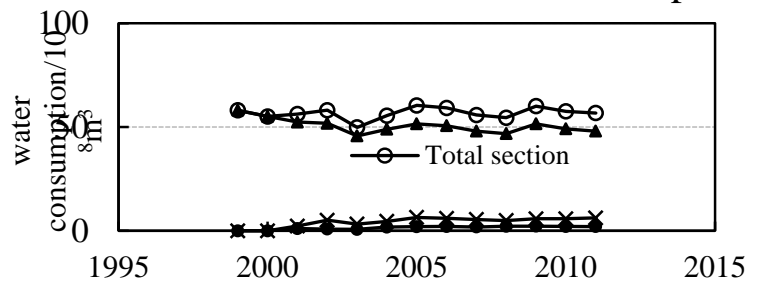

Fig.3 Water consumption of water diversion-recession method in Inner Mongolia reach

\section{Results of water balance method.}

(1) Controlled water quantity. It is mainly occurred between Sanhuhekou and Toudaoguai. There are eight small tributaries or ditches of the Yellow River in this section, Kundulun River, Hademen Ditch, Maobulang Kongdui, Xiliu Ditch, Maobulang Ditch, Wudang Ditch, Hantaichuan, and Kundulun River. Hydrology stations are Taerwan, Hademengou, Guanchangjing, Longtouguai, Tugerige, Dongyuan, Hongtagou and Kundulun respectively.

(2) Uncontrolled water quantity. Uncontrolled water quantity in the Inner Mongolia reach was calculated by mean runoff coefficient multiply uncontrolled catchment area.

(3) Water surface evaporation. It is calculated by observed data of the representative rainfall station and evaporation station year by year.

(4) Water recession. Water recession is mainly occurred from Bayangaole to Sanhuhekou, which includes two parts water quantity of North zongganqu and Xishanzui hydrology station.

(5) Water consumption. The average water consumption from Shizuishan to Toudaoguai in Inner Mongolia reach is 7.544 billion $\mathrm{m}^{3}$. It is 6.567 billion $\mathrm{m}^{3}$ from Shizuishan to Sanhuhekou and 0.976 billion $\mathrm{m}^{3}$ from Sanhuhekou to Toudaoguai, shown in Fig.4.

Comparison of the two methods. Through comparison of water consumption calculation results by the above two methods, it can be seen water consumption calculated by water balance method is larger than that calculated by water diversion-recession method. The average water consumption calculated by water balance method is 7.544 billion $\mathrm{m}^{3}$, while the other by water diversion-recession method is 5.672 billion $\mathrm{m}^{3}$, and the difference is 1.872 billion $\mathrm{m}^{3}$.

\section{Analysis of unbalanced water quantity}

The variables of controlled water quantity, uncontrolled water quantity, water surface evaporation, leakage and so on of water balance equation are assumed the composition parts of unbalanced water quantity, then the above water balance equation change into the following:

$$
W_{\mathrm{L}}=W_{\mathrm{U}}+W_{\mathrm{UB}}-W_{\mathrm{WC}}
$$


Where: $W_{\mathrm{L}}$, lower reach water quantity; $W_{\mathrm{U}}$, upper reach water quantity; $W_{\mathrm{UB}}$, unbalanced water quantity; $W_{\mathrm{WC}}$, water consumption.

Using BP neural network to analyze unbalanced water quantity and water consumption in Inner Mongolia reach, the relationship between rainfall and water consumption is very well in the year from 1999 to 2011, i.e. the more larger rainfall, the more smaller water consumption, and vice versa, shown in Fig.5. Thus rainfall can be regarded as input variable when using BP neural network to calculate water consumption.
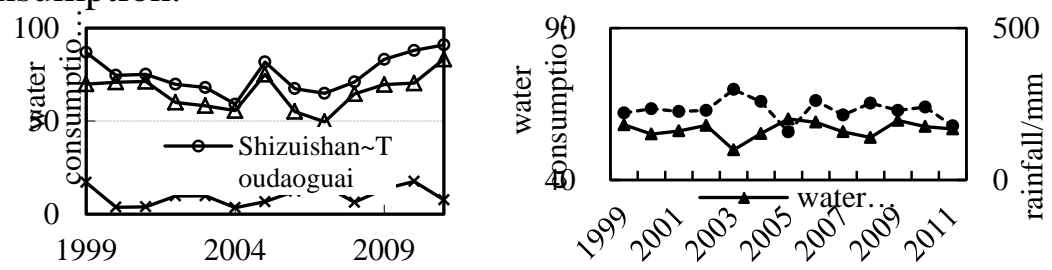

Fig.4 Water consumption of water balance method

Fig.5 Rainfall and water consumption from 1999 to 2011

There are eight input variables, i.e. monthly discharge of Shizuishan hydrology station and Toudaoguai hydrology station, monthly rainfall, unbalanced water quantity and water consumption in Inner Mongolia reach from 1999 to 2008; monthly discharge of Shizuishan hydrology station and Toudaoguai hydrology station and monthly rainfall in Inner Mongolia reach from 2000 to 2009. Where, monthly rainfall in Inner Mongolia reach means the average monthly rainfall of the four hydrology stations along Yellow River, i.e. Shizuishan, Bayangaole, Sanhuhekou and Toudaoguai.

Using the gradient descent method to train, where, learning rate is 0.05 , maximum training cycle is 50000 , mean square error is 0.003 . The simulated monthly water consumption and unbalanced water quantity from 2000 to 2009 in Inner Mongolia reach are shown in Fig.6 and Fig.7. It can be seen that simulation and observation value is very close.

After calibration by the data from 1999 to 2009, monthly water consumption and unbalanced water quantity in the year 2010 and 2011 in Inner Mongolia reach are regarded as verification data. The conclusions are the following: error of unbalanced water quantity in April and July to October is obvious due to large water using amount; simulation and observation value of water consumption from April to October is close, the maximum relative error is about 8\%; while error of simulation and observation value of water consumption from November to March is relatively large.

The large error of water consumption from November to March is mainly affected by the river channel storage increment. Due to the five months are not belong to water using peak, it is hardly effected the annual water consumption. It is suggested that water consumption in April to October should directly use BP neural network simulation, while from November to March should use simulated unbalanced water quantity to indirectly calculate water consumption.

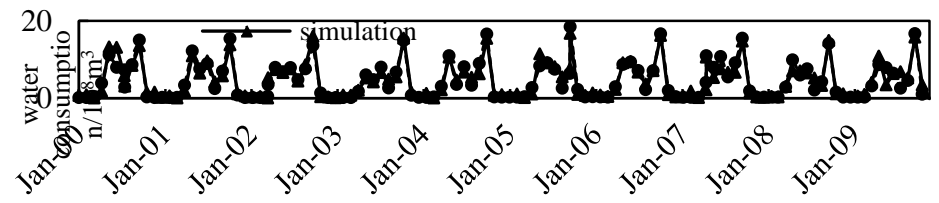

Fig.6 Observed and simulated value of water consumption in Inner Mongolia reach by BP neural network

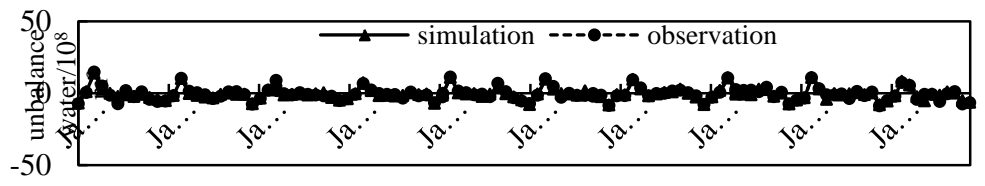

Fig.7 Observed and simulated value of unbalanced water in Inner Mongolia reach by BP neural network 


\section{Conclusions and suggestions}

(1) The average annual water diversion in Inner Mongolia reach from 1999 to 2011 is 6.735 billion $\mathrm{m}^{3}$. Water diversion is mainly occurred in April to November of temporal distribution and Shizuishan to Bayangaole of spatial distribution.

(2) The average annual water recession in Inner Mongolia reach from 1999 to 2011 is 1.071 billion $\mathrm{m}^{3}$. It is mainly occurred in April to November and Bayangaole to Sanhuhekou.

(3) The average water consumption calculated by water balance method is larger than that calculated by water diversion-recession method. The values of the two methods from 1999 to 2011 are 7.544 billion $\mathrm{m}^{3}$ and 5.672 billion $\mathrm{m}^{3}$ respectively.

(4) It is suggested that water consumption in April to October should directly use BP neural network simulation, while in November to March should use simulated unbalanced water quantity to indirectly calculate water consumption by BP neural network.

(5) It is suggested that strengthen verification of entrances and monitoring of water diversionrecession, in order to further analyze the reasons of water consumption difference calculated by two different methods.

\section{Acknowledgements}

Foundation: National Science \& Technology Program (2012BAB02B04), Central Water Resources Project (1261320157643), YRIHR (HKY-JBYW-2014-21).

Author: Jin Shuangyan(1974-), Ph.D and professor, specialized in hydrology and water resources.

\section{References}

[1] Ke Sujuan, Zhou Kangjun. Study on mechanism of integrated water resources management in the Yellow River basin [J], Yellow River. Vol.29, No.1 (2007), 5-7.

[2] Li Guoying. Keep healthy life of the Yellow River [M]. Zhengzhou: Yellow River Water Conservancy Press, 2005.

[3] Hydrology Bureau of Yellow River Conservancy Commission, Yellow River basin hydrology almanac, 1999-2011.

[4] The upper and middle reaches of the Yellow River Administration Bureau, data compilation of water permit regulatory in the Yellow River upper and middle reaches. Oct. 2011.

[5] Zhang Xuecheng, Wang Ling, Si Fenglin. Analysis of water consumption prediction of Yellow River runoff [J], Water Resources and Hydropower Engineering. Vol.32, No.6 (2001): 8-11.

[6] Zhang Xuecheng, Liu Changming, Li Danying. Analysis on surface runoff consumption in the Yellow River [J], ACTA GEOGRAPHICA SINICA. Vol.60, No.1 (2005): 79-86.

[7] Zhang Huimin, Hu Yawei, Hou Aizhong. Numerical simulation of water and sediment change in Ning-Meng reach and the impact of water diversion on water and sediment change in river course [J], Journal of Water Resources \& Water Engineering. Vol.22, No.5 (2011), 41-46.

[8] Luo Qiushi, Zhang Houjun, Zhou Liyan. Effect of water diversion on scour and fill in Ningxia and Inner Mongolia reach of Yellow River [J], Yellow River. Vol.33, No.9 (2011), 22-24. 